\title{
Library Usability in Higher Education: How User Experience Can Form Library Policy
}

\author{
Alison Wiles, Stephen Roberts, and José Abdelnour-Nocera \\ School of Computing \& Technology, University of West London, St Mary's Road, Ealing, \\ London, W5 5RF, United Kingdom \\ \{Alison.Wiles, Jose.Abdelnour-Nocera, Stephen.Roberts\}@uwl.ac.uk
}

\begin{abstract}
The university library is a large socio-technical system with a vital part to play in university life. It has been described as "the social and intellectual heart of campus", with users now able to make use of both the digital and physical aspects of their library. Based on case studies in UK university libraries, this study aims to find out how and to what extent user experience forms part of university library policy, and how it can effectively be incorporated into it. Staff interviews and researcher-administered questionnaires with library users on campus will show the areas where usability issues occur and the gap between users' experiences and expectations of using libraries. These together with analysis of library policies will aim to suggest the factors that a user experience policy should cover.
\end{abstract}

Keywords: University library, usability, user experience.

\section{Introduction}

University libraries will vary greatly in terms of design, layout, location and atmosphere meaning that the student experience will differ greatly from institution to institution. They are the places that students will go to not only to find and borrow materials, but are also places for studying, socialising and even for sleeping [1].There are currently some 120 major universities in the UK [2], with approximately 1.8 million students enrolled as undergraduates in these institutions in 2010 [3]. There are also a further 275,000 postgraduates studying at UK universities [4], making a large and diverse user population for university libraries.

The phrase "the heart of a university" has been used to denote the high regard in which university libraries are held [5], and similarly they have been described as "the social and intellectual heart of campus" [6]. However more than 20 years ago, a study established that students had difficulties using their university library, with some experts believing they were "virtually unusable"[7]. Is this still the case in the early twenty-first century?

University libraries are moving rapidly towards a "self-service" culture. Whereas in the past university library staff would assist or actually carry out searches for books and literature, as well as helping with other library services, the onus is now on users to perform their own searches and find their own material using the interfaces,

P. Campos et al. (Eds.): HWID 2012, IFIP AICT 407, pp. 139-149, 2013.

(C) IFIP International Federation for Information Processing 2013 
databases and search engines available over the world-wide web. Similarly, they are expected to issue books using self-issue machines, and print their own articles. This has arguably simplified library use, while simultaneously bringing in a whole new set of problems.

Usability has been defined as "the appropriateness to a purpose of any particular artefact" [8]. It is a term widely used when referring to computer systems and their interfaces, but it can equally be applied to a non-computerised (or manual) system, or to an article such as a desk or building. Further to this, the International Standards Organization state that "Usability refers to the extent to which a product can be used by specified users to achieve specified goals with effectiveness, efficiency and satisfaction in a specified context of use."[9].The concept of usability can be applied to both the digital and physical spaces of a library, and it is vital that university library systems and interfaces, as well as the library buildings themselves are usable. Every university library will have the various systems and interfaces in place to support library activities with these systems potentially having thousands of users each with differing levels of computer experience, and also library experience. Similarly the physical library needs to be a usable space for both experienced and inexperienced users.

In common with other businesses and institutions, university libraries will have policies to cover areas such as circulation i.e. loan lengths and fines for exceeding these, collection development, user behaviour or conduct, and also computer use. There may also be policies which have the implicit aim of improving users' experiences. Policies have been referred to as “...rules or guidelines that express the limits within which action should occur'[10]. Rather than stating what should or should not be done, policies establish parameters for the decision maker [11]. By having a user experience policy, libraries can make a pledge to their users to make their systems as usable as possible and to do this on an ongoing and regularly reviewed basis, so as to create the best user experience possible.

It has been argued that there will always be a gap in understanding between technology development and its use [12]. Petre et al's [13] investigation into the total customer experience of e-commerce shoppers highlights this when it stresses the importance of thinking beyond just the web interfaces of a system to include other factors such as the delivery of the products or post-sales support. Customers have high expectations in these areas and if disappointed will not return to the website for further purchases, however usable it is. There is therefore potentially a gap between users' expectations and those of the e-commerce operator.

In a study of the usability of London transport systems, Inglesant and Sasse[14] emphasise the need for system usability to be considered and made a priority at the policy design stage. This research centred on users' lived experiences of using London transport systems such as the Oystercard and Congestion Charge scheme, with the researchers' beliefs that each system is an ecology of interfaces and media types, not just websites. In information ecologies, the spotlight is placed not only on technology, but also on the human activities that are served by technology. They are systems of people, practices, values and technologies in a particular environment [15]. An example of an information ecology is a doctor's surgery where doctors, nurses, 
receptionists and patients are the people involved, the practices are medical examinations and treatments, the values are to provide high-quality healthcare to improve health, and the technologies would include patients' records systems or accounting systems to track costs [12]. In the transport usability study, users of the transport systems were interviewed and asked to reflect on their experiences. Observation of users' activities was also undertaken. This once again highlighted the gap between what users and policy makers expect from a system, with the researchers concluding that usability must be considered prior to the implementation of a system [14].

The following diagram shows that there are gaps between some of the expectations of library users compared with those of the policymakers.

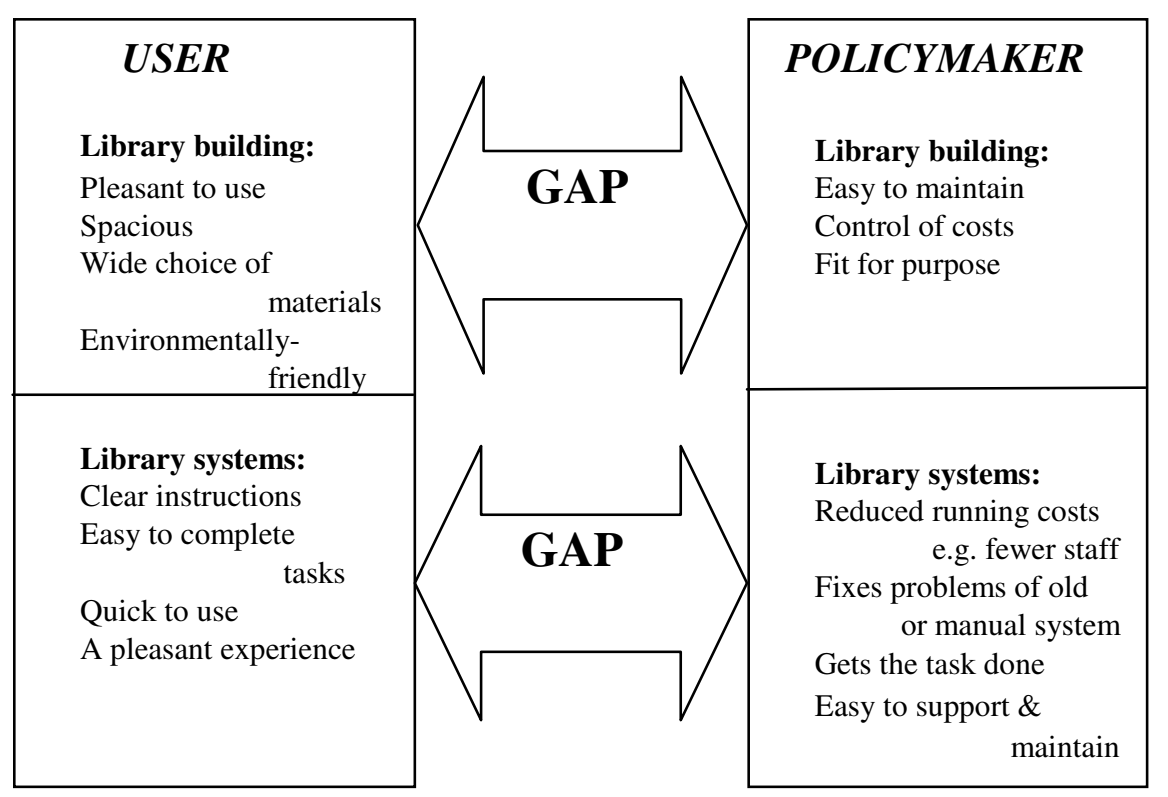

Fig. 1. The gaps between user and policymaker library expectations

This builds on the concept of technological frames which identify the goals and problems that particular groups have with technology. Members of each of these two distinct groups, users and policymakers, will have similar yet not necessarily identical degrees of inclusion in the technological frame [16]. In a library environment, users interact with both the library systems and the library building and have expectations in these areas, while similarly policymakers also have their own expectations. So for example users may expect to have a library system that is quick to use whereas policymakers hope it will fix the problems associated with the system it is replacing. Library users may want an environmentally-friendly building, but policymakers need to be aware of costs and may use cheaper materials. 


\section{Aim of the Study}

The theme of an ecology of interfaces applied to London transport systems can equally be applied to university library systems. Library systems can be complex especially to new students or those with less library experience, with some students even feeling high levels of anxiety when using the university library. They may also experience usability issues, and problems with the library environment, but may be unaware or unsure of how to report these or who to report them to. Similarly, library staff may simply be ignorant of the usability issues that students are facing on a daily basis, and also unaware of problems that exist within the library environment. There is a potential socio-technical gap between what librarians and technologists can offer and what is socially required by users [17]. Having a stated policy regarding usability and user experience can make this gap visible and is one way of moving towards a resolution of these issues.

Past research has looked at the library experience in terms of its environmental factors [1], and there have also been studies of the usability of the library's various systems such as the website utilising a number of research methods. For example Battleson et al [18] investigated the usability of a university library website by asking participants to carry out tasks and to "think aloud", while Thompson [19] remotely observed users interacting with a library website. As previously discussed, researchers in systems in other areas, such as transport, have emphasised the need for a policy regarding usability and user experience [14]. Although it is not unusual for researchers to study the usability of library systems, past studies have tended to concentrate on one particular area such as the library website or catalogue. This study is taking a more holistic view and looking at usability in terms of overall user experience of the physical and digital libraries.

The hypothesis for this study is that a university library user experience policy will help to close the gap between user expectations and experiences. It is an exploratory multiple case study, and aims to find out whether and how user experience can form part of university library policy, and where it is absent how it can effectively be incorporated into policy. It also looks at the factors that the policy should cover by exploring the empirical foundations for such policies. This is investigated from the viewpoint of both the library users and the library stakeholders such as managers and other staff. The research questions that this study is attempting to answer are:

How can user experience best be incorporated into university library policy?

What type of user experience factors should university library policy cover?

\section{$3 \quad$ Method}

In order to answer these questions, this study requires data from both library stakeholders i.e. managers and staff, and also library users i.e. students, academic staff or others. Three university libraries were selected with each being treated as a 
case study. The cases are a range of UK university types with one being a post-1992 (or new) institution, which is a university that was formerly a college of higher education or a polytechnic, but acquired university status as the result of a 1992 act of Parliament. The second case study is a longer established university which is also a member of the 1994 group of research universities, a collection of 13 internationally renowned, research-intensive universities with the aim of promoting excellence in research and teaching [20]. The third is a specialist institution focused on postgraduate study and research. Having these three types should add more range, depth and interest than if similar types were investigated.

Library users at each of the cases were surveyed to reveal their opinions on the library's usability and their own experience of using it. This was done via a questionnaire administered personally by the researcher by stopping and asking students on campus. This is because questionnaires can have a low response rate unless carried out in this way [21], and also because university students are often asked to complete either paper-based or web-based questionnaires, and as a result some universities are actively trying to limit the number of them being carried out. Participants were selected in the library, and although this resulted in a convenience sample, it has been noted that convenience samples are very common especially in social research [22].

The questionnaire firstly asks for background information about the student, for example age, area of study and gender. There are then questions about library use in order to decide whether the participant is a regular or infrequent, experienced or inexperienced library user. The next part of the questionnaire is adapted from Koohang and Ondracek's [23] research into users' views of digital libraries. The questionnaire, designers state that, it is “... a highly valid and reliable instrument". There is a series of Likert scale questions assessing the user's current views on library usability based on 12 properties, followed by more Likert scale questions evaluating the user's perceptions of the importance of each of the 12 properties. This means that it is then possible to calculate the gap between the user's experiences of the usability of the library and their expectations of its usability. The participant is asked to think about the library building and its systems as a single entity when answering the questions. The 12 usability properties include factors such simplicity - whether the library is simple and straightforward to use, user control - whether the user feels in control of his or her actions in the library and knows what to do, and navigability - whether the user can find his or her way around the library and its systems. The other nine factors are:

- Comfort - whether the user feels at ease using the library

- User-friendliness - whether the user believes the library is user-friendly

- Adequacy - does the user feel the information accessed in the library meets their needs?

- Consistency - are the words, terms and actions used in the library consistent?

- Access time - can the user find what they need in a reasonable time?

- Readability - is the information accessed readable and uncluttered?

- Recognition - whether the use recognises the features and functions of the library 
- Visual presentation - is there signage and text to grab the user's attention?

- Relevancy - is the information accessed in the library relevant to the user's requirements?

Finally the participant is asked for any user experience or usability issues that they have encountered. Forty questionnaire responses have been collected at each university. Data collected was analysed statistically using the software, Statistical Package for the Social Sciences (SPSS).

Key members of staff were interviewed at each library in order to gain information about user experience policy. Usability issues are also covered in these interviews, with staff asked to discuss any known problems that occur in library and with its systems. The questions were open-ended in nature so that interviewees can be asked about facts and their opinions [24]. Three interviews are to be carried out at each library, ideally with a manager, a frontline member of staff, and an information technology or systems staff member. The interviews were recorded, transcribed and then analysed via a qualitative content analysis approach which involves searching out the underlying themes in the materials being analysed [22].

Analysis of any policy documents is also to take place at each library to ascertain what has been written regarding policy in relation to usability and user experience. Additionally a survey of all UK university libraries will be carried out to find out what policies are in place across the sector. This will be done by looking at each library's website.

As a part of each case study, empirical data is required to "set the scene" at each library. The researcher observed the day-to-day working of each library to help gather background information and to form specific interview questions for staff.

\section{$4 \quad$ Findings and Anticipated Results}

Currently data has been collected at the three cases. A total of 120 questionnaires have been carried out, 40 at each of the three cases. Library A is the new university, Library B is the postgraduate specialist institution, and Library $\mathrm{C}$ is the member of the 1994 research group of universities. Staff interviews have been carried out at Library $\mathrm{B}$, and the survey of policy documents is underway.

\subsection{The Libraries}

Library buildings remain central to library services [5], and the allocation of space and facilities therein has impacts on how the university library is used. Students now expect different zones for individual silent study or group work. They also expect personal computers (PCs), printers and even café facilities.

Library A is housed in a building attached to other parts of the university. It has four floors, with the ground floor containing a careers advice centre for students, along with a series of library self-issue machines. The first floor is set aside for silent 
study and also has a number of PCs for student use as well as shelves of books. The library helpdesk is on the second floor along with the bulk of the PCs and printers available in the building. Staff offices are also based here. The rest of the space is given over to books. The third and fourth floors also contain book shelves PCs and study areas, but the fourth has provision for group work with some seminar rooms as well as large round tables with screens around to help keep noise to reasonable levels.

Library B was built in the early 1990s, is a stand-alone building on campus, and has three storeys. The ground floor has a number of seminar rooms and an area containing food and drink vending machines with a large table. The first and second floors are similar in layout, and both have individual workspaces with PCs, seminar rooms, and bookstock. Staff are based mainly on the first floor, with helpdesks and self-issue machines here too. Quiet study areas are on the second floor.

Library $\mathrm{C}$ is situated centrally on the university campus and has recently had a large extension added to increase the number of study spaces, PCs and group study rooms available to students. The library is now a mixture of the "old", more traditional library space, and the "new" state-of-the-art space. There are five floors in the building with silent study and group work areas. Level one is where the main entrance, self-issue machines and staff offices are located, and there is also an area containing food and drink vending machines along with seating and tables. Books and PCs are distributed across the five levels, with the third floor having a more relaxed work area containing sofas and armchairs.

\subsection{The Questionnaire Participants}

Questionnaire participants fall into three separate age groups with 50\% aged 18 to 24 years, $37 \%$ in the 25 to 34 years age group, and $13 \%$ aged 35 years or older. Sixty per cent of participants were male and $40 \%$ were female. The vast majority of participants $(84 \%)$ described themselves as frequent library building users, with only $6 \%$ saying that they hardly use the library building, while $55 \%$ were frequent users of the library website.

Fifty-nine per cent of participants were postgraduates, with $31 \%$ being undergraduates. The other $10 \%$ of the sample was made up of research students, staff and alumni. The vast majority of participants, 94\%, were full-time students, and the most popular study subject areas were Engineering (24\%), Business (18\%), and Natural Sciences (12\%).

\subsection{Questionnaire Results}

The three main uses of the library buildings are:

- Borrowing and returning books

- Individual study with library materials

- Accessing computers 
While the three main uses of the library website are:

- Searching the catalogue for books and materials

- Searching the library databases and e-journals

- Browsing electronic books (e-books)

Looking at results in terms of user expectations of library usability, the three areas where users have the highest expectations are:

- Relevancy

- Adequacy

- Simplicity

This means that participants expect the information in their library to be relevant to their needs as well as adequate for their needs. They also expect the library and its associated systems to be simple to use.

Lesser expectations are in the following 3 areas:

- Recognition

- Consistency

- Visual presentation

Meaning that participants are less concerned that they are able to recognise the features and functions of the library, or that the words, terms and actions used in the library are consistent. They are also less concerned that there is signage and text to grab their attention.

These results show that participants are concerned about the information they access and how they access it, and less concerned about the appearance and functionality of the library and its systems. And looking at the three cases separately, the lists of user expectations are very similar suggesting that students have the same issues and concerns regardless of where or what they are studying.

The data can also be analysed by looking at the gaps between user expectations and experience of using their library. Again the results are similar for the three universities with the smallest gaps tending to be as follows:

- Comfort

- Control

- User-friendliness

So participants' expectations and experience are closely matched in terms of feeling at ease using the library, feeling in control of what they are doing, and feeling that the library is user-friendly. 
The largest gaps between expectations and experience tend to occur in these three areas:

- Access time

- Adequacy

- Relevancy

It has already been established that participants have high expectations as far as adequacy of information and relevancy of information. However, these results show that their high expectations in these two areas are not being met by their actual experience thus showing where improvements are likely to be required. The largest gap concerns access time. It would seem that it takes participants much longer than they would like to find the information they need, and again this is an area where improvements are needed.

\subsection{Staff Views}

Interviews with staff at library B have shown that usability testing is carried out whenever possible at the library, but that this is often done in an informal way, for example by asking students to look at a new interface or system and then asking for feedback. Sometimes students volunteer information when a change is made, by telling staff their opinions, and a library Facebook page encourages feedback.

Generally staff believe that a stated policy on user experience is beneficial, and that formal usability testing via methods such as focus groups is valuable. But they also point out that while it is possible to feedback issues to a software supplier, the interface of a library software package will not usually be changed to meet the concerns of one library alone.

Library staff help and advise students with computerised systems such as the library catalogue, and also the manual systems for example the shelving classification system. They note that the library can become busy and at times there is a lack of workspace for students.

\section{Discussion}

Data collection in this study is still ongoing, and as yet it is not possible to fully answer the research questions or to make conclusions.

It has been seen that library users at the three cases value the adequacy and relevancy of the information available in the library, and are less concerned about the appearance and functionality of it. Further analysis of the questionnaire data by age, gender, area of study etc will add further insights, and interviews with staff will no doubt show similarities and contrasts with the students' opinions. Opinions of library usability are lived experiences in that the students or other users have used the library to try to achieve a particular goal. This goal could be as simple as finding a book on a particular topic, or as complex as writing a literature review for a Masters dissertation, 
but it goes beyond their experience of using a computer to include other technological and human factors along with their own experience, capabilities and values [14].

If the university library is viewed as an information ecology, it has students, academic staff, librarians and other support staff as the people involved. Its practices are the provision of information in various formats both physical and digital, while its values are to provide this information in such a way that it is easy to access, readable, relevant and adequate.

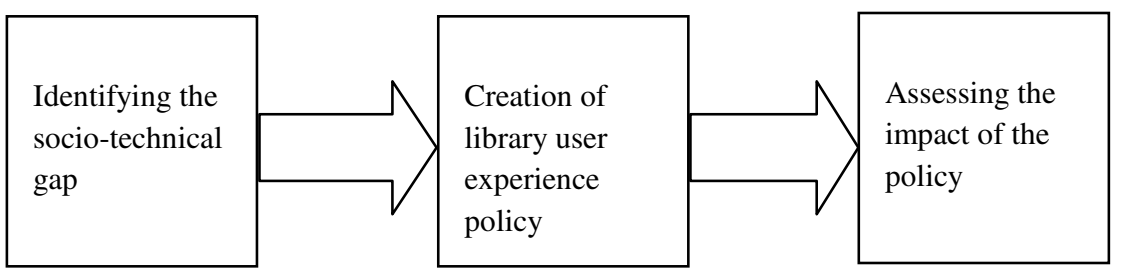

Fig. 2. Creating a library user experience policy

This study aims to shows that the creation of a library user experience policy begins with the identification of the socio-technical gap between experiences and expectations. This is when library usability opinions from staff, students and other library users are gathered, and analysed in conjunction with the existing library policies, and the existing functionality of the library building and systems. The policy needs to be a commitment to library users to continuously strive to improve the library systems and interfaces, and in order to meet users' needs its impact must be assessed on an ongoing basis.

\section{References}

1. Grimes, P., Charters, M.: Library use and the undergraduate economics student. College Student Journal 34(4) (2000)

2. UCAS. About us (2011), http://www.ucas.com/about_us/stat_services/ statisticalfaqs / coverage/faq3 (accessed October 2, 2011)

3. UCAS. Students (2011), http://www.ucas.com/students/wheretostart/nonukstudents / (accessed October 2, 2011)

4. Morgan: Fears for UK research as postgraduate rise is largely a foreign affair (2010), http: / /www. timeshighereducation. co.uk/story. asp? storycode $=41$ 0080 (accessed October 2, 2011)

5. Brophy, P.: The academic library. Facet Publishing, London (2005)

6. Karle, E.: Invigorating the academic library experience: creative programming ideas. College \& Research Libraries News 69(3) (2008)

7. Andrews, J.: An exploration of students' library use problems. Library Review 40(1) (1991) 
8. Brooke, J.: SUS - a quick and dirty usability scale (1996), http: / /www . usabilitynet.org/trump/documents/Suschapt.doc (accessed September 29, 2011)

9. UPA. What is usability? (2012), http://www. usabilityprofessionals.org/ usability_resources/about_usability/definitions_of_ usability.html (accessed November 6, 2012)

10. Mintzberg, H., Quinn, J.: The strategy process: concepts, contexts, cases. Prentice-Hall, New Jersey (1996)

11. Robbins, S., Coulter, M.: Management, 7th edn. Prentice-Hall, New Jersey (2002)

12. Nardi, B., O'Day, V.: An ecological perspective on digital libraries. In: Bishop, A., House, N., Butterfield, B. (eds.) Digital Library Use: Social Practice in Evolution. MIT Press, Cambridge (2003)

13. Petre, M., Minocha, S., Roberts, D.: Usability beyond the website: an empirically grounded e-commerce evaluation instrument for the total customer experience. Behaviour \& Information Technology 25(2) (2006)

14. Inglesant, P., Sasse, M.A.: Usability is the best policy: public policy and the lived experience of transport systems in London. In: Proceedings of HCI 2007 (2007)

15. Nardi, B., O’Day, V.: Information ecologies: using technology with heart. MIT Press, Cambridge (1999)

16. Abdelnour Nocera, J., Dunckley, L., Sharp, H.: An Approach to the Evaluation of Usefulness as a Social Construct Using Technological Frames. International Journal of Human-Computer Interaction 22(1\&2) (2007)

17. Ackerman, M.S.: The intellectual challenge of CSCW: the gap between social requirements and technical feasability. Human-Computer Interaction 15(2) (2000)

18. Battleson, B., Booth, A., Weintrop, J.: Usability Testing of an Academic Library Web Site: A Case Study. The Journal of Academic Librarianship 27(3) (2001)

19. Thompson, S.: Remote Observation Strategies for Usability Testing, Information. Technology \& Libraries (2003)

20. 1994 Group. About us (2012), http: / /www.1994group.ac.uk/aboutus (accessed November 6, 2012)

21. Pickard, A.J.: Research methods in information. Facet, London (2007)

22. Bryman, A.: Social research methods. Oxford University Press (2008)

23. Koohang, A., Ondracek, J.: Users' views about the usability of digital libraries. British Journal of Educational Technology 36(3) (2005)

24. Yin, R.K.: Case study research: design and methods. Sage, Thousand Oaks (2003) 